\title{
VISUALIZE A SUA VOZ: UMA PROPOSTA PARA O ENSINO DE ONDAS SONORAS
}

\section{VISUALIZING YOUR VOICE: A PROPOSAL FOR THE TEACHING OF SOUND WAVES}

\author{
Muriel André de Moura \\ UFMT/Departamento de Física, mourafisica@gmail.com \\ Eduardo Augusto Campos Curvo \\ UFMT/Departamento de Física, curvo@fisica.ufmt.br \\ Ana Flávia Silva de Assis \\ UFMT/Departamento de Física, anaflavia.bio@gmail.com \\ Marcelo Paes de Barros \\ UFMT/Departamento de Física, marcelo.paes@fisica.ufmt.br
}

\begin{abstract}
Resumo
A presente pesquisa objetiva desenvolver e aplicar, para alunos do ensino médio, um produto educacional, um guia didático, para o ensino de ondas sonoras na disciplina de Física. Esse guia, composto de três aulas teóricas e uma prática, culmina com a montagem de um aparato experimental. Esse aparato é montado facilmente a partir de materiais de baixo custo. $O$ mesmo funciona captando as ondas sonoras e as transformando em figuras semelhantes às figuras de Lissajous. Para a avaliação desse produto educacional foi utilizada a teoria da aprendizagem significativa de David Ausubel e a pesquisa qualitativa. Dessa forma, foi possível investigar e obter evidências de aprendizagem significativa por parte dos alunos participantes das aulas.
\end{abstract}

Palavras-chave: Experimento; ensino de física; aprendizagem significativa; ondas sonoras.

\begin{abstract}
The present research aims at the development and application, with students from high school, of an educational product for the teaching of sound waves under the discipline of Physics. This educational product, composed of three theoretical classes and one practical one, culminates with the assemblage of an experimental apparatus. That apparatus is easily mounted from low cost materials. It works by detecting the sound waves and converting them in figures alike the Lissajous figures. In order to evaluate this educational product the theory of meaningful learning from David Ausubel was used, as well as the qualitative research. That way, it was possible to investigate and to collect evidences of meaningful learning by the participating students.
\end{abstract}

Keywords: Experiment; physics teaching, meaningful learning; sound waves. 


\section{Introdução}

Os Parâmetros Curriculares Nacionais abordam que o ensino de Física deve discutir, entre outros temas, a origem do universo e sua evolução, propondo como competências e habilidades a serem desenvolvidas: (i) representação e a comunicação; (ii) investigação e compreensão; (iii) contextualização sociocultural, no sentido de "contribuir para a formação de uma cultura científica e cultural, que permita ao indivíduo a interpretação dos fatos, fenômenos e processos naturais" (MEC, 1999).

A realidade da educação brasileira, com superlotação nas salas de aula, carência de professores de Física, defasada estrutura física, metodológica e didática nas escolas, especialmente da rede pública, faz com que os professores descubram novas formas de "como fazer" educação, adequando-se à proposta projetada pelos parâmetros curriculares.

Mas, como fazer para que as aulas de Física fiquem com o propósito de despertar o interesse pelo conteúdo e colaborar no desenvolvimento de habilidades e competências? Como forma de minimizar essa dificuldade, a utilização de atividades experimentais vem sendo apresentada como possível solução. Uma análise realizada por Araújo \& Abib (2003) sobre as principais publicações em ensino de Ciências constatou que o uso de atividades experimentais vem despertando grande atenção dos pesquisadores, devido à expressiva quantidade de publicações e pela diversidade de enfoques abordados. Os autores destacam alguns dos aspectos fundamentais e acreditam na eficiência desta estratégia, sendo uma delas a capacidade de estimular a participação dos alunos, despertar sua curiosidade e propiciar a construção de um ambiente motivador e agradável.

Considerando que as atividades experimentais favorecem o processo de ensino e aprendizagem, pretendeu-se, neste trabalho de pesquisa, investigar a prática experimental, em especial no ensino de ondas sonoras. Este tema possui grande importância, pois está relacionado diretamente ao cotidiano do aluno e, muitas vezes, acaba sendo não compreendido de forma clara, devido ao alto nível de abstração e falta de experimentos de fácil elaboração.

Assim, o trabalho teve por objetivo a reformulação de um aparato experimental, utilizando materiais de baixo custo, de fácil montagem, com a possibilidade de se trabalhar em sala de aula, analisando a eficiência deste em reproduzir imagens e investigando a sua contribuição para a aprendizagem significativa do conteúdo de ondas sonoras. Para tanto, inicialmente foi investigada a existência de experimentos em artigos de periódicos da área de ensino que relatem a utilização destes no ensino de ondas sonoras, que contribuam para o melhor entendimento dos alunos no estudo do conteúdo.

\section{Fundamentação teórica}

\section{Teoria da Aprendizagem Significativa}

Segundo Moreira (2006), a teoria de Ausubel considera a aprendizagem um processo de organização e integração do material dentro da estrutura cognitiva do aluno. 
Nesse processo, Ausubel destaca o papel que o material já organizado desempenha na aprendizagem de novos conceitos, razão pela qual cabe ao professor levar em consideração os conteúdos já adquiridos pelo aluno. A aquisição de novos conteúdos depende daqueles já existentes, é a partir deles que o indivíduo relaciona e compreende os novos. As novas informações, por sua vez, operam na base do conhecimento já estruturado, planejando uma reconfiguração cognitiva. Desse ponto de vista, o processo de aprendizagem caracteriza-se como uma interação, em que os conceitos já aprendidos funcionam como ancoragem para novos e são ao mesmo tempo modificados por eles.

Para Ausubel, a aprendizagem significativa se dá na medida em que uma nova informação relaciona-se a um componente específico da estrutura cognitiva do indivíduo, a nova informação ancora-se em conceitos ou proposições relevantes preexistentes na estrutura do conhecimento do aprendiz. Esse componente específico é definido como conceito subsunçor. No entanto, a interação realiza-se entre nova informação e conceitos já armazenados e caracterizados como relevantes para essa nova informação (MOREIRA, 2011).

Moreira (2011) ainda destaca quatro tarefas principais no papel desempenhado pelo professor durante a aprendizagem significativa, que se inicia em identificar a estrutura conceitual e proposicional presentes na matéria ensinada e organizá-los hierarquicamente para que possam progressivamente abranger os menos inclusivos, identificar quais os subsunçores relevantes à aprendizagem significativa do conteúdo e que deveriam preexistir na estrutura cognitiva, diagnosticar o conhecimento prévio do aluno, quais os subsunçores relevantes encontram-se na estrutura cognitiva do aluno e; utilizar em seu ensino os recursos e princípios que facilitem a aprendizagem significativa de forma que auxiliem $o$ aluno a assimilar a estrutura conceitual do conteúdo ensinado e a organizar sua própria estrutura cognitiva.

No entanto, e no que se refere a trabalhos publicados sobre as concepções alternativas em alunos de ciências, todos os estudos efetuados nessa área refletem a ideia de que a aprendizagem prévia é decisiva nas novas aprendizagens, isto é, o conhecimento prévio do sujeito e o grau com que o pode ativar nas situações de aprendizagem, determina as suas novas aquisições (VASCONCELOS, 2003).

Ausubel destaca que, conforme a aprendizagem significativa ocorre, conceitos são desenvolvidos, elaborados e diferenciados em decorrência de sucessivas interações, estas, também chamadas de diferenciação progressiva. As ideias mais gerais e mais inclusivas da disciplina devem ser apresentadas no início e depois são progressivamente diferenciadas. Para o autor, é mais fácil para o ser humano captar aspectos diferenciados de um todo mais inclusivo, previamente aprendido, do que chegar ao todo a partir de suas partes diferenciadas (MOREIRA, 2011). Por outras palavras, o conhecimento prévio ou as concepções pré-existentes orientam os alunos na compreensão da nova informação apresentada pelos professores ou pelos manuais. Se as concepções prévias dos alunos se articulam com a versão científica, ocorre apreensão conceptual, mas se entram em conflito com a versão científica, ocorre, então, mudança conceptual (VASCONCELOS, 2003). 
Diante da teoria da Aprendizagem Significativa de David Ausubel, para que um material seja considerado significativo, deve estar organizado no processo de ancoragem de forma que auxilie a aprendizagem e propicie a aquisição de significados por interação. Tendo em vista que os alunos já possuam alguns subsunçores necessários, é por estes que se inicia a aprendizagem significativa dos conteúdos relacionados a ondas.

\section{A prática experimental no ensino}

As orientações curriculares do Estado de Mato Grosso (MATO GROSSO, 2010) destacam a importância do tema som, entre outros, necessitando de uma atenção especial em sala, visto que os jovens se interessam muito por questões a ele relacionadas, tais como, música e cinema. A velocidade com que as novas tecnologias surgem é impressionante, porém é fundamental que o professor de Física tenha clareza de quais são os principais fenômenos envolvidos e os conceitos fundamentais que devem ser construídos, a fim de explorar todas as suas potencialidades.

Diante de alguns desafios, pesquisadores vêm buscando novas formas de como fazer com que as aulas de Física despertem o interesse pelo conteúdo e colaborem no desenvolvimento de habilidades e competências. Como forma de minimizar essa dificuldade, a utilização de atividades experimentais tem sido apresentada como uma possível solução.

Porém, em alguns casos, a prática experimental tem sido negligenciada. Borges (2002) afirma que os estudantes não são desafiados a explorar, desenvolver e avaliar as suas próprias ideias, não se oferece oportunidade de questionamentos acerca da natureza e da investigação científica, pois a experimentação deve ser tratada como uma ferramenta indispensável ao ensino. Para os alunos é importante que descubram o aparato experimental e despertem o entusiasmo de fazer algo com objetos reais. Esse vem sendo um dos grandes desafios atuais do ensino de ciências nas escolas de nível fundamental e médio, isto é, construir uma ponte entre o conhecimento ensinado e o mundo cotidiano dos alunos.

Para Galiazzi (2001, p. 260), o valor da experimentação tem seu foco ainda na construção da teoria resultante da prática, "como se não existisse teoria sem a realização da prática", e propõe o desenvolvimento da teoria junto à prática.

Valadares (2002) relata que um dos grandes desafios atuais do ensino de ciências nas escolas de nível fundamental e médio é construir uma ponte entre o conhecimento ensinado e o mundo cotidiano dos alunos. Segundo o autor, não raro, a ausência deste vínculo gera apatia e distanciamento entre os alunos e atinge também os próprios professores, dessa forma, e defende o uso primordial de experimentos, sendo eles de baixo custo.

Séré (2003) apresenta em seu trabalho como as atividades experimentais são enriquecedoras para os alunos, uma vez que essas práticas atribuem um verdadeiro ambiente lúdico, autonomia aos alunos e ensinam as técnicas de investigação, possibilitando um olhar crítico sobre os resultados. 


\section{Publicações de práticas experimentais}

Araújo \& Abib (2003) relatam a análise de artigos publicados em dois dos maiores periódicos de ensino de Física a nível nacional, o Caderno Catarinense de Ensino de Física e a Revista Brasileira de Ensino de Física, ambos publicados entre os anos de 1992 a 2001. Os resultados mostram uma grande quantidade de artigos publicados, entretanto, na área de conhecimento relacionada ao tema, ondulatória, apenas três artigos são encontrados, cerca de $3 \%$ de todo material analisado.

Errobidart et al. (2009) também apresentaram resultados, de um levantamento realizado em doze fontes de pesquisa, com o objetivo de identificar trabalhos e pesquisas que abordam a experimentação como estratégia de ensino, em particular, para o conteúdo de ondas, com publicações entre o período dos anos de 2002 a 2007. Das quarenta e cinco publicações que abordaram a construção de algum tipo de aparato para aula prática ou a utilização de atividade experimental como estratégia para o ensino, doze relacionavam-se ao estudo de ondas, cerca de $26 \%$ de todo o material analisado.

\section{Ondas}

Hewitt (2002) descreve que uma onda pode ser definida de uma forma simples como movimentos oscilatórios que se propagam num meio, transportando apenas energia, sem transportar matéria. O autor generaliza que de um modo geral uma onda é como qualquer coisa que oscile para frente e para trás, para lá e para cá, de um lado para outro, para dentro e para fora, ligando e desligando, estridente e suave ou para cima e para baixo e que está vibrando em função do tempo.

De acordo com a sua natureza, as ondas classificam-se em dois grupos: ondas mecânicas e ondas eletromagnéticas.

Conforme Hewitt (2002), as ondas mecânicas podem ser descritas como a propagação de vibrações através de um meio material (sólido, líquido ou gasoso). Se não existir tal meio de vibração não é possível existir o som. Sua propagação em um meio material envolve o transporte de energia cinética e energia potencial mecânica. São exemplos comuns ondas de água, ondas sonoras e ondas sísmicas.

Em uma propagação ondulatória, as vibrações podem ocorrer em direção idêntica à da propagação ou em direção perpendicular a ela. Em função disso, as ondas são classificadas quanto a sua direção de vibração. As ondas longitudinais podem ser representadas pelas vibrações que produzem perturbações nas partículas do meio material na mesma direção em que se propagam. As ondas transversais podem ser representadas pelas vibrações que ocorrem perpendicularmente à direção de propagação, formando um ângulo reto com a direção de propagação da onda.

No momento em que ocorre a perturbação do ambiente, as ondas podem ser classificadas quanto ao número de direções de propagação, sendo elas: Unidimensionais, aquelas que se propagam numa só direção; Bidimensionais, aquelas que se propagam num plano; e Tridimensionais, aquelas que se propagam em todas as direções. 
Halliday et al. (2006) apresentam algumas grandezas físicas ou descrições que estão associadas a fenômenos ondulatórios, sendo os principais: a amplitude, a frequência, o período e o comprimento de onda.

\section{Ondas sonoras}

Halliday et al. (2006) descrevem que as ondas sonoras podem ser definidas como a propagação de uma frente de compressão mecânica, ou onda longitudinal, se propagando tridimensionalmente pelo espaço e apenas em meios materiais, líquidos, sólidos ou gasosos.

O som é obtido pela vibração de algo, como, por exemplo, a membrana de alto falante ou as pregas vocais de uma pessoa. Ao vibrar, a fonte produz inicialmente uma compressão do ar na região próxima, com isso as moléculas de ar dessa região começam a vibrar, transmitindo a perturbação para as moléculas vizinhas, e passando, assim por diante.

As "qualidades" que permitem caracterizar um som são a altura, a intensidade e o timbre. A altura é uma qualidade associada ao som grave ou agudo e está diretamente relacionada à frequência da onda sonora. Quanto maior for a frequência, maior será a altura e o som será agudo e quanto menor for a frequência, menor será a altura e o som é grave.

A intensidade é a qualidade que permite caracterizar se um som é forte ou fraco. A intensidade de uma onda sonora indica a quantidade de energia transportada pela onda. Sua unidade de medida é denominada nível de intensidade sonora, expressa em unidade de decibel $(\mathrm{dB})$.

Garcia (2002) explica que a característica que permite reconhecer o som emitido por uma fonte é denominada timbre. O timbre é a qualidade que diferencia dois sons de mesma altura e de mesma intensidade, mas que são produzidos por fontes sonoras diferentes.

\section{Som e o corpo humano}

O ouvido humano é um receptor capaz de captar frequências que vão de cerca de $20 \mathrm{~Hz}$ (muito grave) até $20 \mathrm{kHz}$ (muito agudo). Estes limites, no entanto, variam com a idade e com o indivíduo. Porém, o ouvido humano não possui a mesma eficiência em detectar todas as frequências sonoras, quando comparado a outros animais.

Segundo Durán (2003), o ouvido humano é um órgão extremamente sensível, que converte um fraco estímulo mecânico, produzindo em um meio externo, em estímulos nervosos. Grande parte do sistema auditivo esta localizado no interior da cabeça, sendo dividido em ouvido externo, ouvido médio e ouvido interno.

As ondas sonoras, ao atingirem a orelha, são dirigidas para o interior do canal auditivo, na extremidade do qual existe uma membrana, semelhante à pele de um tambor, denominada tímpano. O tímpano é tão delicado e sensível que variações de pressão muito pequenas da onda sonora são suficientes para colocá-lo em vibração. Por exemplo, o ouvido humano é capaz de captar uma frequência de $1000 \mathrm{~Hz}$ à amplitude mínima da pressão de aproximadamente $3.10^{-5} \mathrm{~Pa}$ (SEARS \& ZEMANSKI, 2008). 
Essas vibrações são comunicadas a um pequeno osso chamado martelo, que por sua vez, aciona outro osso chamado bigorna, e finalmente faz vibrar o terceiro osso chamado estribo. Com esse processo, as vibrações são sucessivamente ampliadas, tornando nosso ouvido capaz de perceber sons de intensidade muito baixa.

Finalmente, as vibrações amplificadas chegam ao ouvido interno, que tem a forma de um caracol, chamado cóclea, revestida por pelos muito pequenos. Em seu interior existe um líquido que facilita a propagação do som. As ondas sonoras colocam os pelos em vibração, estimulando células nervosas que, por meio do nervo auditivo, enviam os sinais ao cérebro. Dessa maneira, a pessoa tem a percepção do som.

A voz emitida pelo ser humano tem sua origem nas vibrações de duas membranas, denominadas cordas vocais. As cordas vocais entram em vibração quando 0 ar, proveniente dos pulmões, é forçado a passar pela fenda existente entre elas. Podemos controlar a frequência do som que emitimos, modificando a tensão das cordas vocais. As vibrações dessas cordas são comunicadas ao ar existente nas diversas cavidades da boca, da garganta e do nariz e aos músculos próximos a elas. A combinação de todas essas vibrações determina o timbre da voz, que é característica de cada pessoa.

Durán (2003) explica que a produção da fala é o resultado de um conjunto de processos que envolvem diversas partes do organismo, essas partes, além de estarem interconectadas, experimentam interações entre elas. A fala é consequência do movimento reduzido, aumentado e não interligado dessas partes e a respiração proporciona a matéria prima para a fala.

\section{Material e métodos}

\section{Universo da amostra e etapas da pesquisa}

A pesquisa foi realizada na cidade de Sinop, no Estado de Mato Grosso, na Escola Estadual Nilza de Oliveira Pipino. O conteúdo gerador da pesquisa foi ondas sonoras, destinado às turmas de $2^{\circ}$ ano do Ensino Médio. A turma, selecionada por sorteio, era composta por vinte e cinco $(\mathrm{N}=25)$ alunos.

A pesquisa, de caráter qualitativo, teve como objetivo buscar a interpretação dos significados atribuídos pelos sujeitos. Segundo Moreira (2002), a pesquisa qualitativa busca a interpretação dos significados atribuídos pelos sujeitos a suas ações em uma realidade socialmente construída, obtido através de observações participativas, onde o pesquisador fica imerso no fenômeno de interesse.

O estudo foi dividido em duas etapas, a primeira referente à ferramenta de coleta dos dados e a segunda à análise das respostas descritas pelos alunos. Os instrumentos de coleta foram: notas de aulas registradas no caderno de campo, avaliações escritas referentes ao conteúdo programático e opinário sobre a sequência didática desenvolvida.

As respostas da avaliação escrita foram classificadas e organizadas em categorias, onde as respostas classificadas como satisfatórias foram elaboradas em conformidades com os conceitos trabalhados, as parcialmente satisfatórias foram elaboradas com uso 
parcial dos conteúdos e as insatisfatórias não foram elaboradas segundo os conceitos aprendidos. A categoria não respondeu abrange questões que não foram respondidas pelos alunos.

A sequência didática foi divida em quatro aulas de uma hora e cinquenta minutos cada, sendo três aulas teóricas e uma aula destinada à prática experimental.

Na primeira aula realizou-se um levantamento do conhecimento prévio dos alunos sobre o conteúdo de ondas, verificando a capacidade em identificar os tipos de ondas, diferenciar e reconhecer o som da onda do tipo mecânica e montar um mapa conceitual. A segunda aula também foi destinada à parte teórica, onde foram apresentadas as características relacionadas ao som e quais delas estão associadas ao corpo humano, como o sistema fonador e auditivo. Essa aula foi finalizada com a confecção de outro mapa conceitual. Na terceira aula foi apresentada, de forma superficial, a teoria de Fourier e sua aplicação no cotidiano. Nesta etapa da pesquisa utilizou-se o laboratório de informática a fim de demonstrar um aplicativo que simula a sobreposição de ondas e a formação de ondas compostas.

A quarta aula foi prática, destinada à montagem do aparato experimental, por meio do roteiro de montagem. No término da aula experimental foi entregue a cada aluno uma ficha que continha nove questões referentes à metodologia utilizada nas aulas sobre o tema de ondas sonoras. Foi solicitado que cada aluno respondesse, sem a necessidade de identificação. As respostas das questões um a seis foram dadas através de alternativas de múltipla escolha e as demais questões foram respondidas de forma descritiva. Após as questões serem respondidas, foram analisadas e tabeladas.

\section{Construção do aparato experimental}

O aparato experimental foi construído com materiais de fácil acesso e baixo custo, com o objetivo de explorar os conceitos relacionados ao som e às diferentes figuras formadas. O aparato é semelhante ao proposto por Valadares (2002), cujo objetivo é "converter sons em imagens".

Os materiais necessários para a construção do aparato são: Lata de metal com 75 $\mathrm{mm}$ de diâmetro e $80 \mathrm{~mm}$ de comprimento; elásticos de borracha; régua de $30 \mathrm{~cm}$ r; balão de festa; caneta laser; prendedor de roupa; espelho plano de dimensões $1 \mathrm{~cm}$ x $1 \mathrm{~cm}$ e Fita adesiva (dupla face). Para a realização dos testes foram necessários: Aparato experimental reelaborado; micro computador portátil com sistema operacional Windows 7; Caixas de som amplificadas (caixa de grave de um home theater 5.1 Satélite As-5101 e caixa amplificada Voxstorm Vsu150); e Software gerador de áudio (Audio Sweep Generator-Versão 3.5.4.29) (Figura 01).

A montagem do aparato e a sua aplicação em aulas de Física foram compilados na forma de um Guia Didático "Visualize sua voz" (MOURA e CURVO, 2015). 


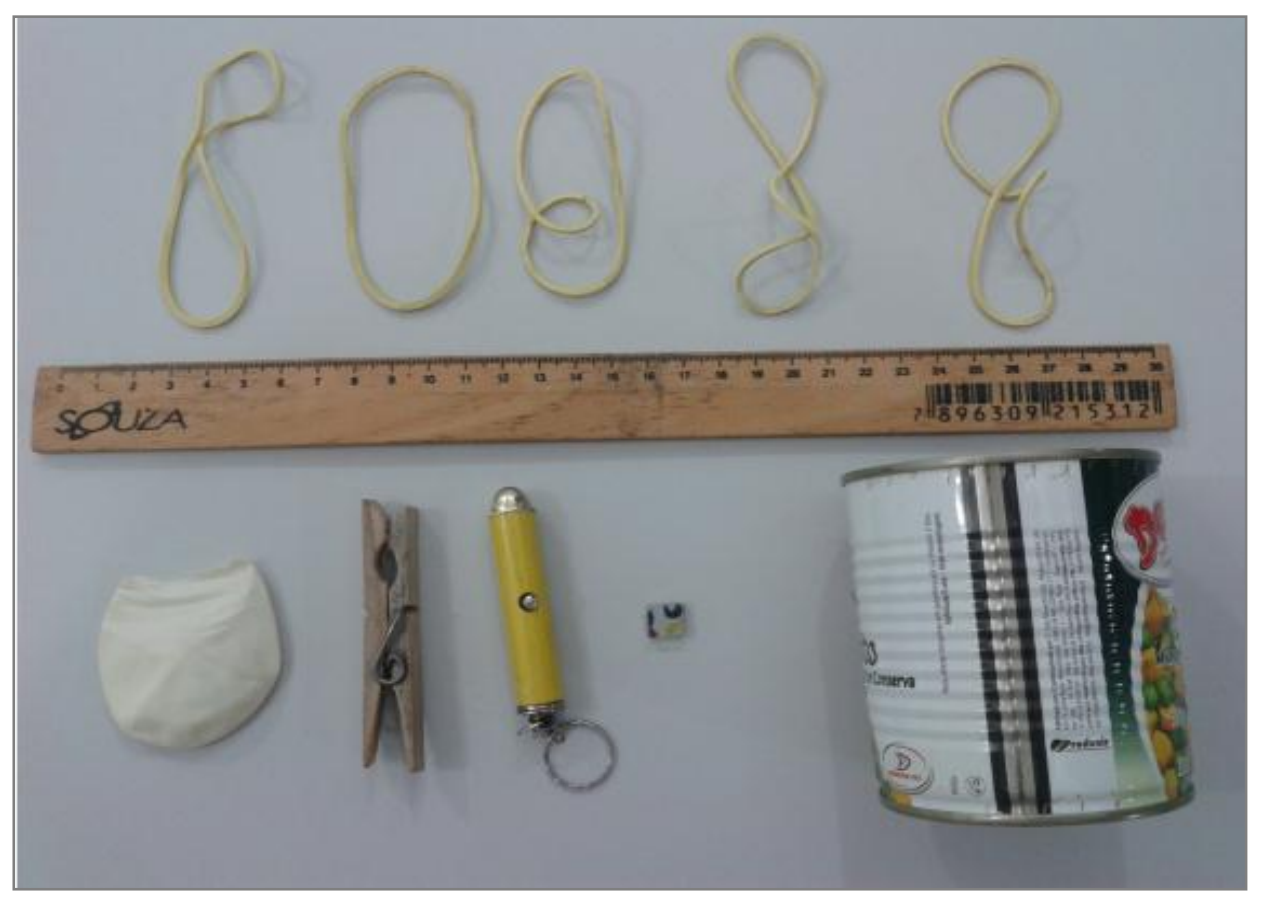

Figura 1: Materiais utilizados no experimento.

Para iniciar a montagem do aparato deve-se: 1) retirar ambas as tampas da lata, cortar o balão na parte do bico e cobrir uma das extremidades da lata, prendendo com o elástico de borracha; 2) colar o pedaço do espelho no centro da membrana do balão; 3) colocar a lata em uma das extremidades da régua, fixando com dois elásticos. $\mathrm{Na}$ outra extremidade da régua será fixada a caneta laser, também com um elástico; 4) ajustar a caneta laser com o prendedor de roupa e acioná-lo de modo que fique direcionado para o centro do espelho (Figura 02).

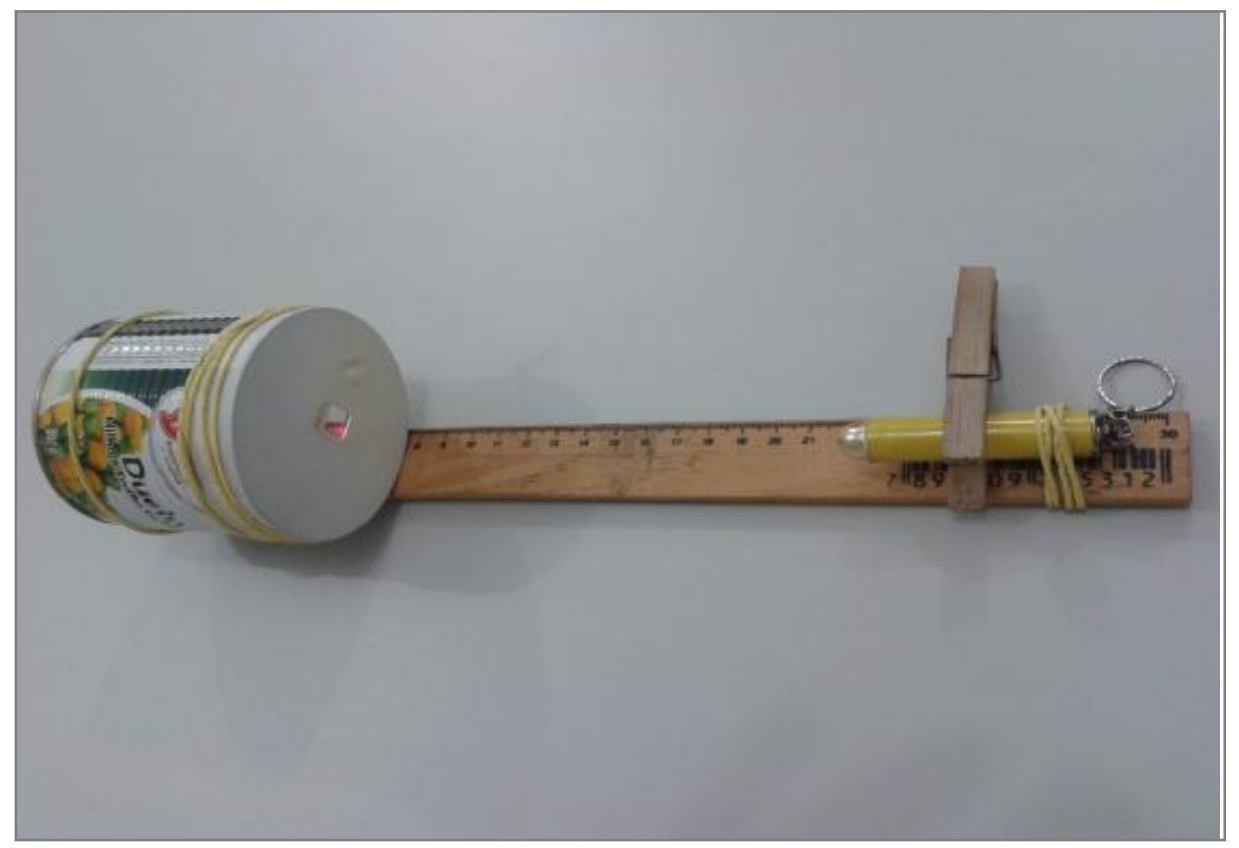

Figura 2: Aparato experimental devidamente montado e ajustado para seu funcionamento. 


\section{Revisão Bibliográfica}

Para a revisão bibliográfica o autor realizou um levantamento das publicações que abordavam as diferentes formas de se realizar atividades experimentais, do ano de 2008 a 2013. Para tanto utilizou como fonte de pesquisa treze revistas científicas nacionais da área de ensino: Caderno Brasileiro de Ensino de Física; Revista ABRAPEC; Revista Brasileira de Educação; Revista Brasileira de Ensino de Física; Revista Ciência e Cognição; Revista Ciência e Cultura; Revista Ciência e Educação; Revista Ciência e Ensino; Revista Eletrônica de Ciências; Revista Ensaio; Revista Experiências em Ensino de Ciências; Revista A Física na Escola; Revista Investigações em Ensino de Ciências.

\section{Resultados e discussões}

\section{Pesquisa Bibliográfica}

Após identificar as publicações que tratam de atividades experimentais, das treze revistas utilizadas na pesquisa bibliográfica, não foi possível evidenciar publicações relacionadas com atividades experimentais, em cinco delas.

Dos setenta e cinco artigos publicados que abordavam a construção de experimento para aulas práticas, ou a utilização do mesmo como estratégia para o ensino de Ciências ou Física, apenas seis estavam relacionados ao tema de ondas mecânicas. Nesta pesquisa não foram contabilizados os artigos que abordavam o ensino de ondas de natureza eletromagnética.

Dos artigos que foram encontrados, e que se enquadram ao tema geral de ondas mecânicas, sonoras e acústicas, três artigos foram publicados na "Revista Brasileira de Ensino de Física", revista que é voltada à melhoria do ensino de Física em todos os níveis de escolarização:

1. Lüdke et al. (2012) descrevem as modificações de um clássico experimento, cujo objetivo é de medir a velocidade do som ao ar livre, através da medida de tempo de propagação de ondas sonoras, captadas por dois microfones. Os autores relatam a metodologia adequada para trabalhar com este experimento e a forma de como construir os circuitos de produção e de captação de sinais de ultrassons em $40 \mathrm{kHz}$. O experimento permite determinar a velocidade com melhor precisão e explorar o efeito Doppler-Fizeau qualitativamente, o que não se pode ser feito com ondas sonoras audíveis;

2. Gomes e Lüdke (2011) relatam a construção de um experimento de baixo custo para o estudo da teoria de ondas estacionárias em cordas vibrantes, através do uso de um aparato eletrônico relativamente simples, baseado na realimentação eletromagnética, possibilitando verificar tanto a harmonia das ondas estacionárias, quanto a relação numérica existente entre os harmônicos;

3. Piubelli et al. (2010) apresentaram a construção de aparato experimental de baixo custo para simular a influência das características físicas inerciais e elásticas do meio e na velocidade de propagação de uma onda mecânica. Este experimento também demonstra 
a dependência da velocidade de propagação com as propriedades inerciais e elásticas de um meio sólido.

Outros três artigos foram encontrados na revista A Física na Escola, como suplemento semestral da "Revista Brasileira de Ensino de Física", destinada a apoiar as atividades de professores de Física do Ensino Médio e Fundamental:

1. Moura e Neto (2011) descrevem uma ferramenta que auxilia no processo de ensino aprendizagem relacionado ao tema acústica, composta por sugestões de ensino por meio da montagem de instrumentos musicais construídos de materiais de baixo custo e que possam ser montados em sala de aula. Os autores relatam discussões sobre a abordagem da acústica de forma que seja contextualizada por meio da história;

2. Cavalcante et al. (2012) relatam um experimento simples e de fácil reprodução, com o intuído de determinar a velocidade do som no ar através do eco. Em sua construção são utilizados tubos de diferentes comprimentos e para análise e coleta de dados do experimento é utilizado um programa de análise sonora, o Audacity. Os resultados obtidos neste experimento conduzem precisões e exatidões inferiores a 1\%, o que viabiliza sua implantação como um bom recurso didático na compreensão de fenômenos relacionados à acústica;

3. Novicki et al. (2011) propõem atividade de aprendizagem sobre ondas sonoras de fácil aplicação a estudantes de nível médio. A atividade utiliza a aquisição automática de dados através do uso do computador e é possível determinar a velocidade de uma fonte sonora baseada no efeito Doppler- Fizeau.

Através dos resultados da pesquisa bibliográfica é possível notar a presença de publicações que estão relacionadas à introdução, utilização e confecção de experimentos, a fim de auxiliar e minimizar as dificuldades de aprendizado em Física.

As sugestões sobre a utilização da prática experimental são tão amplas que elas podem ser realizadas com materiais de baixo custo ou até mesmo em conjunto a outros locais de uma escola, como laboratório de ciências, laboratório de informática ou até mesmo a própria sala de aula. Entretanto, foram selecionadas apenas as publicações que relatavam a construção de experimentos com materiais de baixo custo e que estivessem diretamente relacionados com o tema de ondas sonoras, tema cujo número de artigos encontrados não é tão grande quando comparado a outros temas da disciplina de Física.

\section{Testes do aparato experimental}

Como resultado do teste onde a variação da frequência gerada foi entre $1 \mathrm{~Hz}$ e 200 $\mathrm{Hz}$, o aparato experimental apresentou sua eficiência em gerar imagens a partir da frequência de $11 \mathrm{~Hz}$, continuando até o fim da escala definida. As imagens formadas possuíam diversos formatos, porém foi observado que em determinadas frequências as imagens se moviam, mudando simultaneamente a sua forma, e em outras foi possível gerar imagens imóveis.

Esta etapa de testes foi registrada em vídeo, indicando os determinados intervalos de frequência, as imagens sofrendo variação de tamanho e de forma geométrica, a 
velocidade e o sentido de movimento. Esta etapa do teste experimental está disponível e pode ser visualizada através do link: http://www.youtube.com/watch?v=5_OPMnmKYyQ.

No segundo momento do teste, a variação da frequência gerada foi entre $200 \mathrm{~Hz}$ e $20 \mathrm{kHz}$. Nesta faixa o aparato experimental demonstrou sua eficiência em gerar imagens até a frequência de $732 \mathrm{~Hz}$, imagens com similaridade às reproduzidas no teste anterior, porém, ocorrendo em maior número de vezes o fenômeno onde a figura geométrica mudava seu tamanho, alternando seu sentido de movimento. Esta etapa de teste do experimento também pode ser visualizada através do link: http://www.youtube.com/watch?v=vYGvTqj3Ro4.

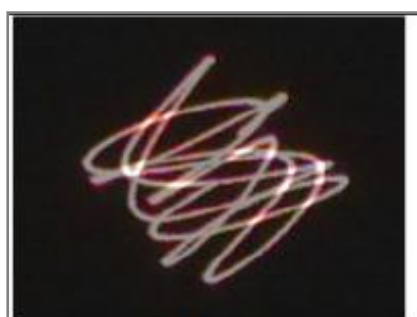

A

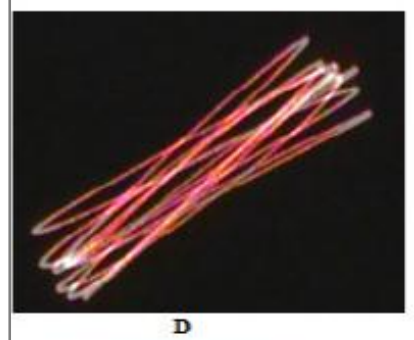

D

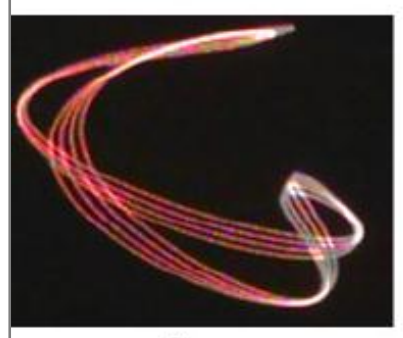

G
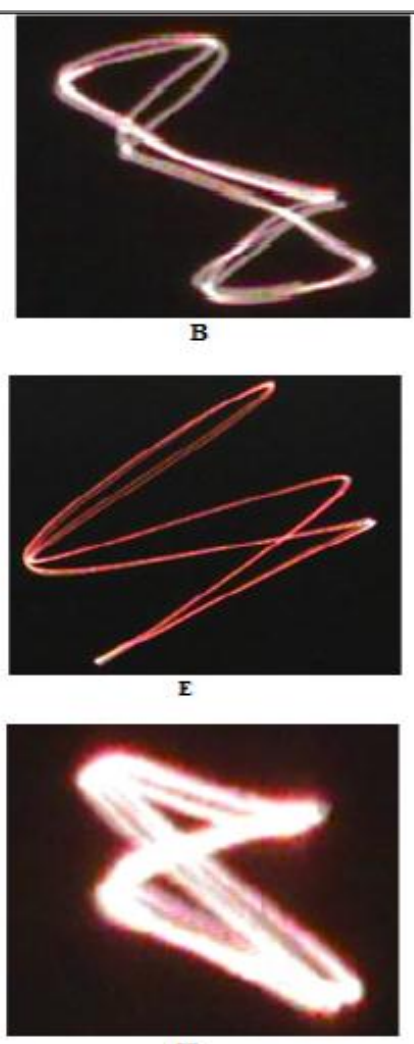

H
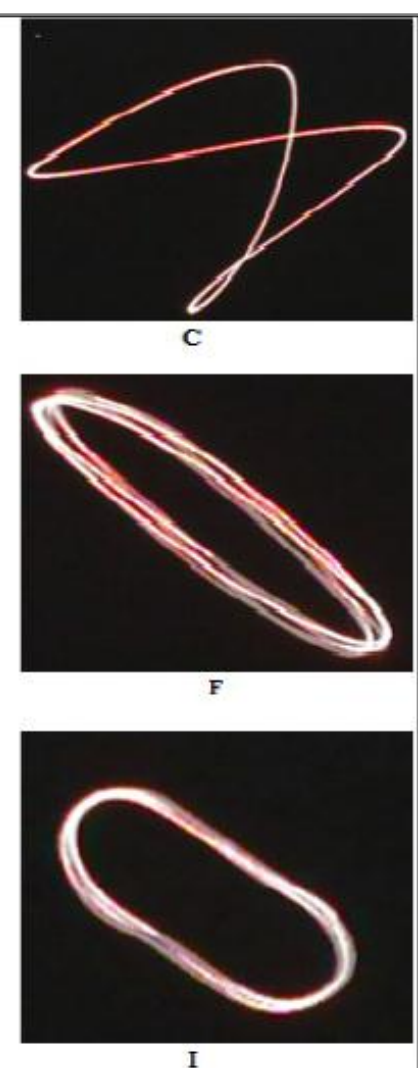

Figura 3: Imagens formadas utilizando-se diferentes frequências: a) $21 \mathrm{~Hz}$, B) $64 \mathrm{~Hz}, \mathrm{C}) 103 \mathrm{~Hz}$, D) $40 \mathrm{~Hz}$, E) $68 \mathrm{~Hz}$, F) $190 \mathrm{~Hz}$, G) $100 \mathrm{~Hz}, \mathrm{H}) 148 \mathrm{~Hz}$ e I) $127 \mathrm{~Hz}$.

Outro teste foi realizado utilizando a frequência de $105 \mathrm{~Hz}$, onde é possível reproduzir uma imagem geométrica semelhante a um círculo. Notou-se que, no momento em que é alterado o volume da caixa amplificada, a figura geométrica formada tem seu tamanho modificado. Desta forma, pode se concluir que as dimensões da figura formada está relacionada à intensidade da onda sonora. $\mathrm{O}$ vídeo desta etapa também está disponível em: http://www.youtube.com/watch?v=PTpRE0CZuD4.

O último teste foi realizado com músicas de gêneros diferentes, Música Popular Brasileira (MPB), Preciso Me Encontra de Cartola, Rock, Crazy Train de Ozzy Osbourne, e Rap, com canções diversos de Eminem. Os links de demonstração desta etapa do 
experimento com as respectivas

são: http://www.youtube.com/watch?v=UQ4COYfLmNg; http://www.youtube.com/watch?v=hFJ66-bwwDk; http://www.youtube.com/watch?v=H6CDTVI7bK4.

Utilizando músicas de distintos gêneros foi possível notar o comportamento do experimento através das imagens formadas. Como não possuem eficiência nas frequências acima de $732 \mathrm{~Hz}$, as músicas que são compostas, ou que possuem grande quantidade de notas do tipo grave, se destacam e formam um grande número de imagens. As músicas que possuem poucas notas do tipo grave, formam menor quantidade de imagens.

A música de gênero MPB foi a que apresentou um comportamento mais suave em suas imagens formadas, enquanto o gênero Rap apresentou um comportamento mais agitado em suas imagens formadas, tendo em vista que é composta por muitas notas musicais de tom grave.

Durante este teste foi possível notar que algumas das figuras reproduzidas pelo aparato experimental são semelhantes às figuras estudadas por Jules Antoine Lissajous em 1857. Essas figuras são criadas decorrentes a um gráfico produzido por um sistema de equações paramétricas que descreve um complexo movimento harmônico. Tais equações são utilizadas como um dos recursos mais importantes na manutenção, reparação e ajuste de equipamentos eletrônicos, a partir da visualização das grandezas que variam com o tempo em seus circuitos nos osciloscópios.

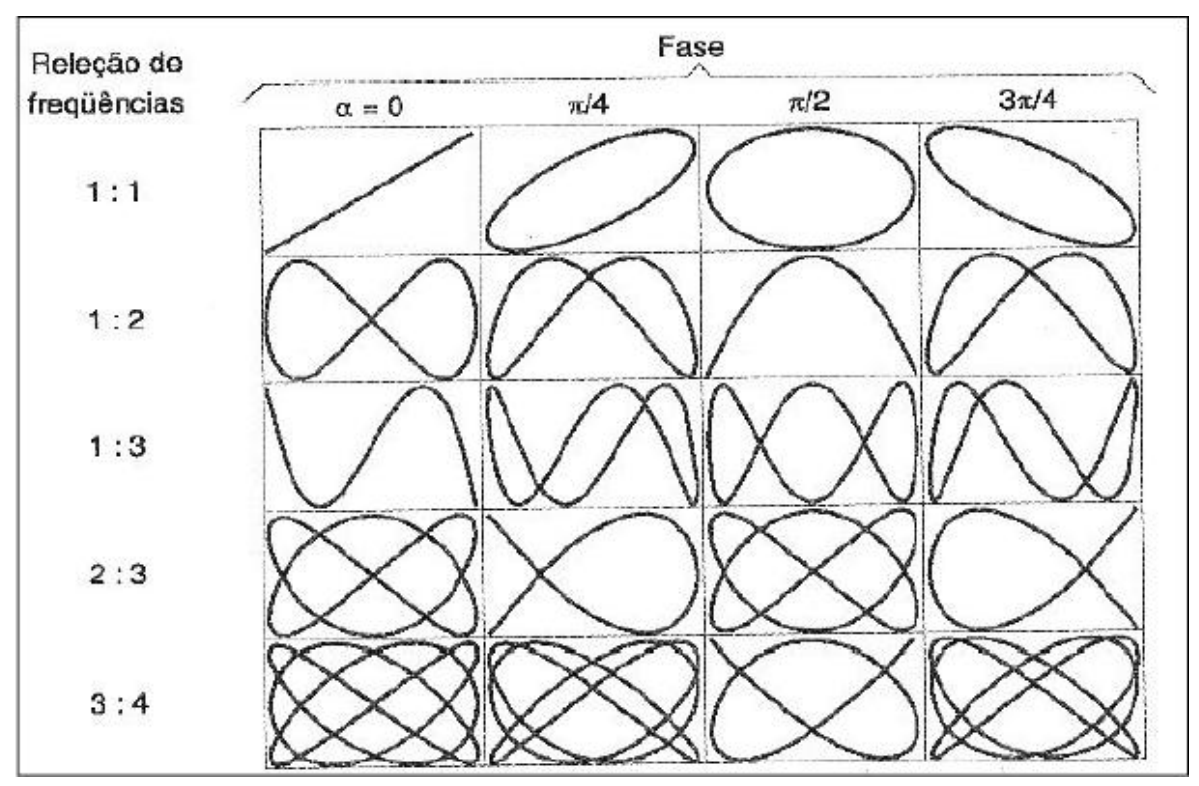

Figura 4: Figuras de Lissajous. Fonte: La web de física. Disponível em: $<$ http://forum.lawebdefisica.com/attachment.php?attachmentid $=6572 \& d=1362594173>$. Acessado em 15/07/2014.

Entretanto, não foi possível encontrar uma relação matemática que explicasse o comportamento do aparato diante da frequência por ele recebida. Outra observação foi que ao realizar novamente o teste em outra data e com outro aparato experimental não foi possível reproduzir as mesmas figuras criadas anteriormente, utilizando-se as mesmas frequências. Este fato se dá pelo motivo de que a superfície vibratória (membrana feita de 
balão) não possui uma uniformidade quanto à espessura de seu material ou até mesmo podendo mudar o seu poder de elasticidade, devido ao tempo exposto que fica esticado, ou pela força utilizada para esticar a mesma, ou ainda pelas condições ambientais.

Como não havia disponível algum instrumento apropriado para medir, ou verificar, o quanto a superfície estava esticada, não houve a possibilidade de descrever os modos normais de vibração com suas respectivas frequências e imagens. Destarte, o par frequência $\mathrm{x}$ imagem formada, varia de experimento para experimento.

Entretanto, apesar de haver variação quanto à correspondência entre frequência sonora utilizada e padrão de figura criado, a família de figuras apresentadas no trabalho pode ser obtida em outras montagens experimentais, porém, em frequências diferentes.

Vale ressaltar que este trabalho pode também ser destinado a alunos surdos ou que possuam algum grau de deficiência auditiva. $O$ aparato aqui apresentado possibilitaria que esses alunos "visualizassem" o som de outra forma.

\section{Proposta de Ensino de Física}

Foi entregue a cada componente do grupo um roteiro de atividades. Esse roteiro foi respondido individualmente de forma descritiva, utilizando todo o conhecimento apresentado durante as aulas teóricas, podendo o grupo, debater sobre as questões e os diferentes pontos de vista sobre os fenômenos decorrentes.

O roteiro foi dividido em quatro etapas. Na primeira etapa, os próprios componentes do grupo utilizaram o experimento e nas demais etapas foi utilizado apenas um dos experimentos montados pelos alunos, este escolhido por sorteio, e utilizado em conjunto a uma caixa de som amplificada pelo professor, no centro da sala.

As questões deste item foram elaboradas com o objetivo de orientar a participação direta dos alunos na atividade experimental sobre ondas sonoras. Neste primeiro momento o aluno era o responsável por reproduzir o som, o estudante começa a falar e reproduzir sons no instrumento experimental.

Os resultados do primeiro bloco de questões podem ser observados na tabela 01 . A questão 1.1 abordou a formação e o formato da imagem formada onde, 09 estudantes responderam de forma satisfatória e 16 parcialmente satisfatória. A 1.2 explorou o responsável pelo fenômeno e a explicação para tal, neste quesito 13 estudantes responderam de forma satisfatória e 12 parcialmente satisfatória. 22 estudantes apresentaram respostas satisfatórias, 02 parciais e apenas 01 considerada insatisfatória para a questão 1.3 que tem como objetivo identificar e classificar o fenômeno. A questão 1.4 abrangeu a diferença na formação das imagens ao alterar a voz, para este item houveram 10 respostas consideradas satisfatórias e 15 parciais. 
Tabela 01: Classificação das respostas referente ao item 01, no qual os alunos utilizam sua própria voz para reproduzir as imagens com o aparato experimental.

\begin{tabular}{ccccc}
\hline Questão & Satisfatória & Parcialmente Satisfatória & Insatisfatória & Não respondeu \\
\hline 1.1 & 09 & 16 & 0 & 0 \\
\hline 1.2 & 13 & 12 & 0 & 0 \\
\hline 1.3 & 22 & 02 & 1 & 0 \\
\hline 1.4 & 10 & 15 & 0 & 0
\end{tabular}

Para realizar as questões do item 2 foi utilizada a caixa de som amplificada em conjunto com o aparato experimental, onde as imagens formadas tiveram origem no som que saia do alto falante. No primeiro momento foram colocados dois tipos de músicas diferentes. A primeira música do gênero Clássica e a segunda do gênero Rock, ambas tocadas por aproximadamente 3 minutos. Foi solicitado que os alunos observassem as imagens e, em seguida respondessem as questões, conforme tabela 02.

A questão 2.1 abordou a percepção dos estudantes diante da diferença entre as músicas, somente pelas imagens formadas. Para este item, as 25 respostas foram consideradas totalmente satisfatórias. Na questão 2.2 todos os estudantes responderam parcialmente sobre a "qualidade" do som associada a esses gêneros musicais.

Tabela 02: Classificação das respostas referentes ao item 02 , no qual é utilizada a caixa amplificada e reproduzidas músicas de gêneros diferentes.

\begin{tabular}{ccccc}
\hline Questão & Satisfatória & $\begin{array}{c}\text { Parcialmente } \\
\text { Satisfatória }\end{array}$ & $\begin{array}{c}\text { Insatisfatória } \\
\text { Não } \\
\text { respondeu }\end{array}$ \\
\hline 2.1 & 25 & 0 & 0 & 0 \\
\hline 2.2 & 0 & 25 & 0 & 0 \\
\hline
\end{tabular}

As questões do item três (tabela 03) foram referentes ao momento em que se gira o botão do volume da caixa amplificada, em que foi solicitado aos alunos que observassem se as imagens reproduzidas sofreram algum tipo de alteração e, em seguida, respondessem questão 3.1 sobre a diferença na formação das imagens e por que isso ocorre, 15 estudantes responderam de forma satisfatória e 10 responderam parcialmente. A questão 3.2 referia-se sobre a "qualidade" do som associada à alteração do "volume" da caixa de som e 12 estudantes responderam satisfatoriamente e 13 de forma insatisfatória.

Tabela 03: Classificação das respostas referente ao item 03, na qual é realizada a alteração da intensidade sonora.

\begin{tabular}{ccccc}
\hline Questão & Satisfatória & $\begin{array}{c}\text { Parcialmente } \\
\text { Satisfatória }\end{array}$ & Insatisfatória & Não respondeu \\
\hline 3.1 & 15 & 10 & 0 & 0 \\
\hline 3.2 & 12 & 0 & 13 & 0 \\
\hline
\end{tabular}


O quarto item (tabela 04), que finalizou a aula experimental, teve o objetivo de realizar uma comparação entre diferentes tipos de sons. Para esse experimento foi utilizado o software Audio Sweep Generator, capaz de reproduzir ondas puras e compará-las com a etapa anterior onde foram utilizadas músicas. O objetivo deste item foi de apresentar aos alunos um som formado por ondas puras e confrontar as imagens formadas por elas com as imagens de sons formados por ondas compostas. Foram reproduzidas ondas puras, onde a frequência não foi alterada e diante desses sons foi pedido aos alunos para visualizar e representar as imagens formadas, respondendo a questão 4.1 sobre as comparações com as imagens anteriores, onde todos os estudantes responderam de forma satisfatória. A questão 4.2 referia-se e o porquê da reação dessas imagens diante das ondas puras. Neste quesito, 19 responderam de maneira satisfatória e 06 insatisfatoriamente.

Tabela 04: Respostas referentes ao item 04, no qual são utilizadas ondas puras, a fim de diferenciá-las de ondas compostas.

\begin{tabular}{ccccc}
\hline Questão & Satisfatória & $\begin{array}{c}\text { Parcialmente } \\
\text { Satisfatória }\end{array}$ & Insatisfatória & Não respondeu \\
\hline 4.1 & 25 & 0 & 0 & 0 \\
\hline 4.2 & 19 & 0 & 6 & 0 \\
\hline
\end{tabular}

Avaliação dos Alunos da Sequência de Ensino-Aprendizagem

A Tabela 05 apresenta a opinião dos alunos com relação às atividades desenvolvidas.

Tabela 05: Percepções dos alunos ao final da sequência didática.

\begin{tabular}{lccc}
\multicolumn{1}{c}{ Questões } & Sim & Não \\
\hline 1-Encontrou dificuldade em entender algum conceito durante a aula & 03 & 22 \\
teórica? & &
\end{tabular}

2-Apresentou alguma dificuldade para realizar o que o roteiro de

$01 \quad 24$

montagem do experimento pedia para ser feito?

\begin{tabular}{lll}
\hline 3-Teve alguma dificuldade para entender o que o roteiro de & 03 & 22
\end{tabular} atividades experimental pedia para ser feito?

4-A atividade experimental ajudou na compreensão dos conteúdos $\quad \begin{array}{lll}25 & 0\end{array}$ abordados na aula teórica?

5-Você gostou de participar de uma aula com demonstrações em $\quad 25 \quad 0$. Física?

6-Você encontrou facilidade em realizar uma revisão do conteúdo $\quad 21 \quad 04$ da aula através dos mapas conceituais? 
Da questão um até a questão seis, foi possível notar que grande parte dos alunos não encontrou dificuldade em entender o conceito apresentado nas aulas teóricas, em montar o experimento e em seguir as instruções do roteiro de atividade experimental.

Por unanimidade os alunos confirmaram que a realização da atividade experimental melhorou as suas compreensões dos conceitos apresentados nas aulas teóricas e que 0 mapa conceitual facilitou as revisões das aulas anteriores.

Sobre a participação anterior em aulas experimentais, apenas um aluno respondeu já ter realizado alguma experiência em sala de aula onde ocorreu a confecção de um pêndulo eletrostático. Os demais vinte e quatro alunos responderam ter sido essa a primeira vez que realizavam uma atividade experimental, sendo que todos concordaram que a utilização da atividade experimental teria ajudado a explicar o conteúdo abordado. Sobre o que gostaram e não gostaram durante a sequência didática, todos responderam que dentre todas as aulas, a prática, a montagem e utilização do experimento, foi a mais prazerosa.

Com relação à aula que não apreciaram, os alunos citaram a aula teórica, em que foi apresentada a Série de Fourier, etapa trabalhada com gráficos e demonstração de cálculos e sua aplicação no conteúdo de ondas compostas.

\section{Considerações finais}

Um dos intuitos deste trabalho foi confeccionar um aparato experimental construído a partir de materiais de baixo custo e que fosse de fácil montagem. A utilização desse material busca auxiliar o professor no momento em que apresenta o tema de ondas sonoras.

A revisão bibliográfica constatou a existência de uma pequena quantidade de publicações relacionadas à construção de experimentos que possam ser utilizados para o tema ondas sonoras.

O aparato experimental foi montado a partir de um modelo existente na literatura e passou por algumas alterações e testes. As alterações possibilitaram que os alunos pudessem montar 0 aparato experimental em poucos minutos, não necessitando de ferramentas.

Após a realização dos testes foi possível concluir que a eficiência do aparato experimental em transformar ondas sonoras em imagens esteve entre as frequências de $11 \mathrm{~Hz}$ a $732 \mathrm{~Hz}$. As imagens formadas apresentaram variedades diversas, podendo ser classificadas como regulares e não regulares, fixas ou móveis.

O guia didático "Visualize sua voz" elaborado para a utilização do aparato em sala de aula, fundamentado na Teoria de Aprendizagem Significativa, constitui-se de uma sequência didática que realiza a conexão entre teoria e experimento. A funcionalidade da sequência didática foi auxiliada pela utilização de mapas conceituais e testada pela aplicação de questionários.

A análise dos questionários forneceu indícios de que ocorreu a presença de aprendizagem de forma significativa. Porém, não se pode afirmar o grau desta 
aprendizagem obtida. Esses resultados afirmam algo já relatado em outros trabalhos, que a utilização de práticas experimentais é de grande importância e não pode deixar de ser utilizada, considerada uma atividade indispensável durante as aulas de ciências para um curso mais eficaz.

\section{Referências}

ARAÚJO, M. S. T. \& ABIB, M. L. V. S. Atividades Experimentais no Ensino de Física: diferentes enfoques, diferentes finalidades. Revista Brasileira de Ensino de Física, vol. 25, no. 2, Junho, 2003.

BORGES, A. T. J. Novos rumos para o laboratório escolar de Ciências. Caderno Brasileiro de Ensino de Física, v. 19, n.3: p.291-313, dez. 2002.

MEC, Ministério da Educação. Parâmetros Curriculares Nacionais: Ensino Médio, 1999. CAVALCANTE, M. A.; PEÇANHA, R.; LEITE, V. F. Determinação da velocidade do som no ar através do eco. Revista Física na Escola, v. 13, n. 1, p.19- 23, maio 2012.

DURAN, J. E. R. Biofísica: Fundamentos e aplicações. São Paulo: Pearson Prentice Hall, 2003. 318p.

ERROBIDART, H. A.; GOBARA, S. T.; ERROBIDART, N. C. G. Levantamento dos trabalhos que descrevem a Utilização da experimentação como estratégia para o Ensino de ondas (2002-2007). XVIII Simpósio Nacional de Ensino de Física, Vitória, ES, 2009.

GALIAZZI, M. C. Objetivos para as atividades experimentais no Ensino Médio. Ciência \& Educação, v.7, n.2, p.249-263, 2001.

GARCIA, E. A. C. Biofísica. São Paulo: SARVIER, 2002. 387p.

GOMES, C. A.; LÜDKE, E. Uso da ressonância em cordas para ensino de física. Revista Brasileira de Ensino de Física, v. 33, n. 3, 2011.

HALLIDAY, D.; RESNICK, R.; WALKER, J. Fundamentos de Física 2: Gravitação, Ondas e Termodinâmica. $7^{\text {ạ }}$ Edição Rio de Janeiro: Ltc - Livros Técnicos e Científicos, Editora S.A, 2006. 292 p.

HEWITT, P. G. Física Conceitual. Porto Alegre: Bookman, 2002.

LA WEB DE FÍSICA. Figuras de Lissajous. Disponível em: <http://forum.lawebdefisica.com/attachment.php?attachmentid=6572\&d=1362594173> Acessado em 15/07/2014.

LÜDKE, E.; CAUDURO, P. J.; VIEIRA, A. M. V.; ADORNES; R. B. Velocidade do som no ar e efeito Doppler em um único experimento. Revista Brasileira de Ensino de Física, v. 34, n. 1, 2012.

MATO GROSSO. SECRETARIA DE ESTADO DE EDUCAÇÃO. Orientações Curriculares: Ciências da Natureza e Matemática. Cuiabá: Defanti, 2010.

MOREIRA, M. A. Teorias da Aprendizagem. São Paulo: EPU, 2006. 
MOREIRA, M. A.; MASINI, E. F. S.; Aprendizagem significativa: a teoria de David Ausubel. São Paulo: Moraes. 2011.

MOURA, D. de A.; NETO, P. B. O ensino de acústica no Ensino Médio por meio de instrumentos musicais de baixo custo. Revista Física na Escola, v. 12, n. 1, p.12-15, maio 2011.

MOURA, M. A.; CURVO, E. A. C. Visualize a sua Voz: uma proposta para o ensino de ondas sonoras. Dissertação de mestrado, Programa de Pós-Graduação em Ensino de Ciências Naturais, UFMT, 2015.

NOVICKI, A.; LATOSINSKI, E. da S.; POGLIA, R. Determinação da velocidade de uma fonte sonora. Revista Física na Escola, v. 12, n. 1, p.4-7, maio 2011.

PIUBELLI, L.; ERROBIDART, H. A.; GOBARA, S. T.; ERRODIDART, N. C. G Simulador de propagação de ondas mecânicas em meios sólidos para o ensino da física. Revista Brasileira de Ensino de Física, v. 32, n. 1, 2010.

SEARS, F. W.; ZEMANSKY, M. W.; YOUNG, H. D.; FREEDMAN, R A. Física II: Termodinâmica e Ondas. v.2, 10 ed. São Paulo, SP: Pearson Addison Wesley, 2008.

SÉRÉ, M.G; COELHO, S.M; NUNES, A.D. O papel da experimentação no ensino da física, caderno brasileiro de ensino de física. V. 20, n.1: p.30-42, abril. 2003.

VALADARES, E. C. Física mais que divertida. Inventos eletrizantes baseados em materiais reciclados e de baixo custo. Belo Horizonte: Ed. da UFMG, 2002.

VASCONCELOS, Clara; PRAIA, João Félix; ALMEIDA, Leandro S.. Teorias de aprendizagem e o ensino/aprendizagem das ciências: da instrução à aprendizagem. Psicologia Escolar Educacional. Campinas , v. 7, n. 1, p. 11-19, jun. 2003 . Disponível em <http://pepsic.bvsalud.org/scielo.php?script=sci_arttext\&pid=S1413$85572003000100002 \&$ lng=pt\&nrm=iso $>$. acessado em 27 jun. 2016.

Submissão: 01/10/2016

Aceite: 22/03/2017 